\title{
Interaction between the Intermediate Host of Schistosomiasis in Brazil Biomphalaria glabrata (Planorbidae) and a Possible Competitor Melanoides tuberculata (Thiaridae): I. Laboratory Experiments
}

\author{
Alexandre Giovanelli, Marcus Vinícius Vieira*, Cesar Luiz Pinto Ayres Coelho da Silva/ ${ }^{+}$
}

\author{
Departamento de Biologia, Instituto Oswaldo Cruz-Fiocruz, Av. Brasil 4365, 21045-900 Rio de Janeiro, RJ, Brasil \\ *Departamento de Ecologia, Universidade Federal do Rio de Janeiro, Rio de Janeiro, RJ, Brasil
}

The biological control of Biomphalaria glabrata, intermediate host of Schistosoma mansoni, is one the accepted options to fight schistosomiasis. One of the most promising candidates to control B. glabrata is the snail Melanoides tuberculata, a potential competitor. However, the mechanisms of interaction between the two species are not clear. Our objective is to determine if $\mathrm{M}$. tuberculata indeed compete with $\mathrm{B}$. glabrata, using two laboratory experiments. In Experiment 1, we tested the effect of the presence of $\mathrm{M}$. tuberculata on the fecundity and mortality rates of $\mathrm{B}$. glabrata. In Experiment 2, we tested if there was a direct or indirect interaction between the two species. In Experiment 1, M. tuberculata was eliminated after the peak in reproductive activity of B. glabrata. In Experiment 2, B. glabrata produced more egg masses when raised with $\mathrm{M}$. tuberculata. The conditions leading to this unexpected positive effect of $\mathrm{M}$. tuberculata on the fecundity of $\mathrm{B}$. glabrata need further clarification, but emphasize that detailed studies of the interaction between these species in the conditions of the local environment should be considered.

Key words: Biomphalaria glabrata - Melanoides tuberculata - competition - schistosomiasis

Certain pulmonate snails are intermediate hosts of Schistosoma spp., the digenetic trematode responsible to schistosomiasis in man. Competitors of pulmonate snails have been used for biological control of host populations (WHO 1984, Madsen 1990, Sturrock 1995, Pointier \& Giboda 1999). In the West Indies, the thiarid Melanoides tuberculata was effective in the elimination or reduction of populations of Biomphalaria glabrata, the intermediate host in the cycle of schistosomiasis (Pointier et al. 1989, 1991a, Pointier \& McCullough 1989, Pointier \& Guyard 1992, Pointier 1993, Schlegel et al. 1997). However, in Venezuela M. tuberculata was introduced in 20 sites, but only in three sites was Biomphalaria spp. eliminated or effectively reduced (Pointier et al. 1991c). In Brazil, the first occurence of M. tuberculata was reported in 1967, in Santos, State of São Paulo. After that, this snail has spread to other localities, probably as a result of successive accidental introductions associated with fish farms (Vaz et al. 1986). However, there are few reports of interaction between $M$. tuberculata and species of the genus Biomphalaria in Brazil.

Gomez et al. (1990) observed a negative effect of thiarids on B. glabrata in a laboratory experiment, which was attributed to an undetermined substance liberated by thiarids. Conversely, Moné et al. (1986) observed a

${ }^{+}$Corresponding author. Fax: +55-21-2560.6474. E-mail: cesarcs@ioc.fiocruz.br

Received 26 June 2001

Accepted 19 December 2001 positive effect of $M$. tuberculata on B. glabrata. When raised with $M$. tuberculata and other mollusks, $B$. glabrata reached a larger size and produced more cercaria of S. mansoni (Moné 1991). These results point to the dangers of species introductions for biological control based on poor knowledge and weak assumptions of species interactions. The effectiveness of $M$. tuberculata for biological control of B. glabrata in a specific environment can be evaluated only when the ecology of these species and the nature of their interactions are understood.

Here, our objectives were to test two hypotheses: that $M$. tuberculata has a negative effect on the growth and demography of $B$. glabrata $(\mathrm{H} 1)$, and that a substance liberated by $M$. tuberculata causes this negative effect (H2). The second hypothesis was proposed previously for Thiara granifera, another thiarid (Prentice 1983, Gomez et al. 1990, Perez et al. 1991). Two laboratory experiments were performed to test these hypotheses.

\section{MATERIALS AND METHODS}

Individuals of $M$. tuberculata and B. glabrata were collected in streams of two valleys in the municipality of

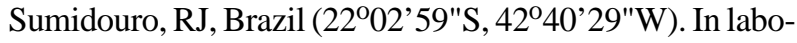
ratory, these individuals were raised in 74 × 237 × $330 \mathrm{~mm}$ plastic containers with 21 of dechlorinated tap water. Dehydrated lettuce and rodent food pellets (3-4 mm large) were provided ad libitum, and temperature varied between 22 and $27^{\circ} \mathrm{C}$ during the study. Containers were checked at least every two days to remove dead individuals, to guarantee ad libitum food, and that rodent pellets stayed on the bottom. The water was changed every fortnight to avoid any crowding effect, when the number of egg masses, embryos, young and adults was counted. These 
were the experimental conditions of the following experiments.

Experiment 1: growth and demography of $B$. glabrata raised with $M$. tuberculata - This experiment was designed to test H1, that M. tuberculata has a negative effect on $B$. glabrata. Three groups with three replicates each were formed: B 10 B. glabrata; M: 10 M. tuberculata; BM: 5 B. glabrata and 5 M. tuberculata.

A replicate was a plastic container with ten young individuals. Only young of the two species were used. Individuals of $M$. tuberculata with less than $3 \mathrm{~mm}$ of length and individuals of $B$. glabrata less than $2 \mathrm{~mm}$ in diameter were used, corresponding to about 15 days old. All snails were raised in the laboratory, and were allowed to grow and reproduce freely during the experiment. Only dead individuals were removed in Experiment 1. The diameter of B. glabrata and the length of M. tuberculata were measured every fortnight, followed by the water change in the containers. The number of egg masses, embryos, young and dead adults of B. glabrata also was counted every fortnight, and divided by the number of individuals present providing three measures of fecundity and one of mortality. M. tuberculata is a viviparous species, and thus only the numbers of young and dead adults were counted.

Experiment 2: mortality rates and fecundity of $B$. glabrata raised in direct and indirect contact with $M$. tuberculata - This experiment was designed to test $\mathrm{H} 2$, that $M$. tuberculata liberates a substance that affects $B$. glabrata negatively. Only individuals of $M$. tuberculata with more than $19 \mathrm{~mm}$ of length and individuals of $B$. glabrata with more than $15 \mathrm{~mm}$ in diameter were used, corresponding to adult individuals. Six groups with two replicates each were formed. The containers of the replicates were divided in two by a wire mesh of $1 \mathrm{~mm}^{2}$, except for group BMU, as follows: BM: $10 \mathrm{~B}$. glabrata at one side and $10 \mathrm{M}$. tuberculata on the other side, to determine indirect effects of individuals of other species; BB: $10 \mathrm{~B}$. glabrata at one side and $10 \mathrm{~B}$. glabrata on the other side, to control for indirect effects of individuals of the same species; MM: 10 M. tuberculata at one side and 10 $M$. tuberculata on the other side, to control for indirect effects of individuals of the same species; B: $10 \mathrm{~B}$. glabrata all at one side, the other side empty. A control for any indirect effects of individuals on the other side of the container, regardless of the species; M: $10 \mathrm{M}$. tuberculata all at one side, the other side empty. A control for any indirect effects of individuals on the other side of the container, regardless of the species; BMU: 10 B. glabrata and $10 \mathrm{M}$. tuberculata in an undivided container, without the wire mesh, to compare direct and indirect effects between the two species.

The number of adult individuals was kept constant during Experiment 2 by removing newborn individuals and by replacing dead by new adults. The number of adult individuals replaced, and the number of egg masses, embryos, and young of B. glabrata was counted every fortnight. Mortality was not measured directly in Experiment 2 , but can be inferred from the absolute number of replaced individuals per fortnight. The number of egg masses, embryos, and young was divided by the number of adult individuals present, providing three measures of fecundity for B. glabrata. Because M. tuberculata is a viviparous species, only the number of young and dead adults was counted.

Statistical analyses - Except for survival in Experiment 1, demographic variables of B. glabrata were compared between groups by Analysis of Variance (ANOVA) with replicates nested within groups. There was a marked difference in the fecundity measures of $B$. glabrata before and after the 4th fortnight. Thus, in addition to group and replicate a third factor, named "period", was introduced to consider potential differences between these periods. Survival in Experiment 1 had a linear relationship with time, hence only for this variable time was treated as a covariate, comparing groups by Analysis of Covariance (ANCOVA). In ANCOVA, the effect of time is removed by a process similar to regressing each variable against time and then comparing the intercepts of the regression lines of each variable. Tukey test was used for pair wise comparisons (Sokal \& Rohlf 1995). Survival in Experiment 1 was measured as a proportion, and hence was arcsinsquare root transformed prior to statistical analyses. The other fecundity variables were counts of dead individuals, egg masses, and young, and hence were log-transformed (Sokal \& Rohlf 1995).

\section{RESULTS}

Experiment 1 - All individuals of $M$. tuberculata in group BM raised with $B$. glabrata died at the 4th fortnight of the experiment, right after the peak in production of young by B. glabrata. In the control group M, where $M$. tuberculata was raised alone, populations persisted 21 months after the beginning of the experiment in variable degrees $(50 \%, 70 \%$, and $90 \%$ of the original populations in the three replicates). In the group $\mathrm{M}$, mortality begun only at the 15 th and 17 th fortnights in two replicates, and at the 4 th fortnight in one replicate. $M$. tuberculata did not reproduce in any group.

Mortality of B. glabrata in the control group B and in the experimental group BM began at the 4th fortnight (Fig. 1a). After that, survival was significantly higher in group B (Table I, Fig. 1a). Populations of B. glabrata were monitored until the 13th fortnight, when the last surviving individuals died.

In the first four fortnights, the production of egg masses, embryos, and young of B. glabrata was higher in the experimental group BM than in the control group B (Figs 1b,c,d), but this difference was not significant (Table I). In all groups, egg masses and embryos of B. glabrata appeared at the 2 nd fortnight, and adults at the 3rd fortnight of the experiment. The peak of egg mass and young production occurred one fortnight after their first appearance (Figs 1b, c, d).

Experiment 2 - There was no mortality of $M$. tuberculata in any of the groups during the 11 fortnights of the experiment. Group M, where M. tuberculata was raised alone on one side of the container, differed from the others by a higher production of young between the 3rd and 4th fortnights (Fig. 2c). Accordingly, there was a significant difference between groups in the production of young, and a significant interaction groups $\mathrm{x}$ period (Table II). Tukey a posteriori tests detected significant 

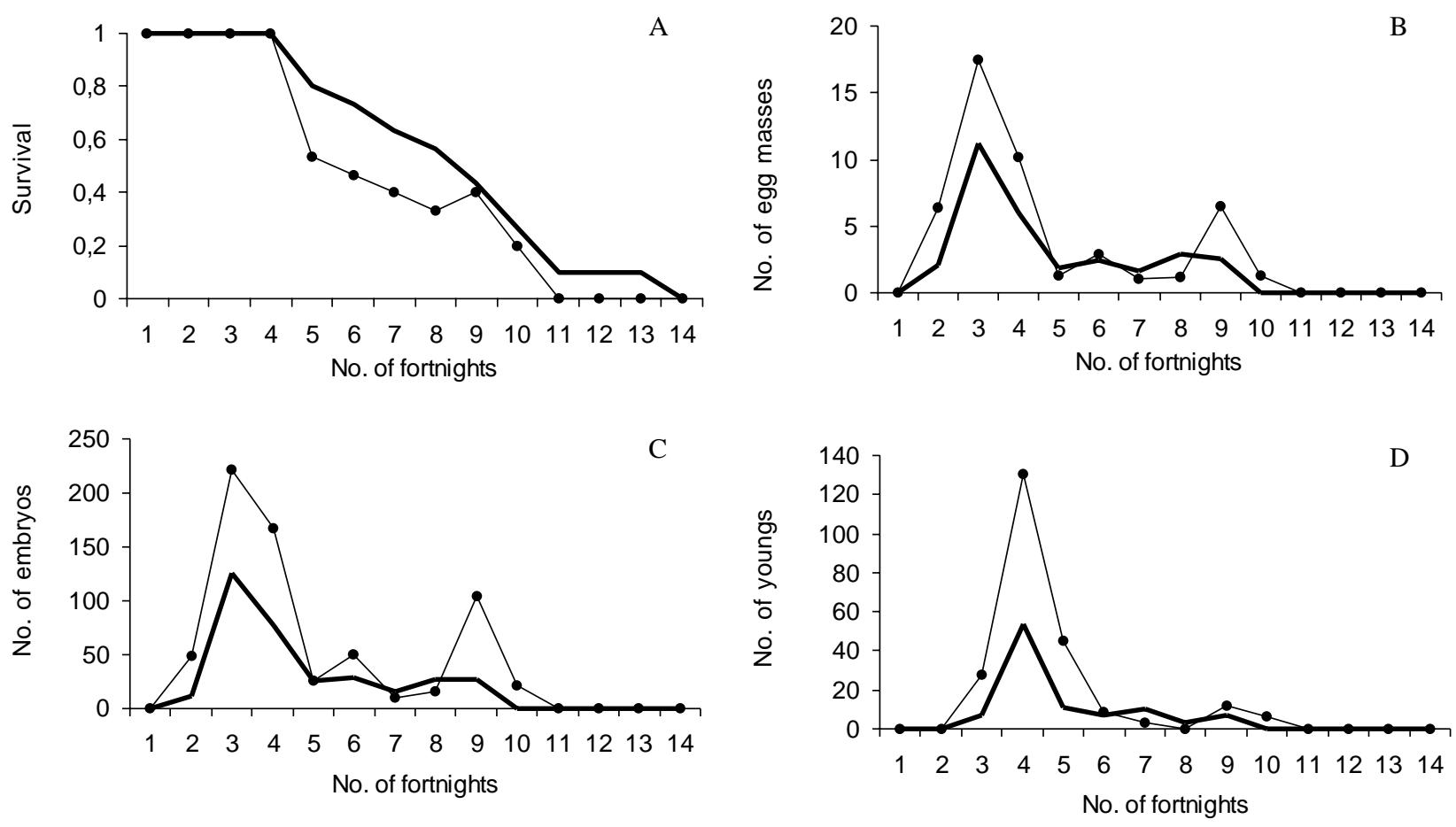

Fig. 1: survival (A), number of egg masses (B), embryos (C) and young (D) of Biomphalaria glabrata raised alone (group B) and with Melanoides tuberculata (group BM), during the 14 fortnights of the first experiment. Mean value of the replicates was used for each variable.

TABLE I

Effect of Melanoides tuberculata on the survival and fecundity of Biomphalaria glabrata (groups)

\begin{tabular}{|c|c|c|c|c|c|c|c|c|c|c|}
\hline & \multirow{2}{*}{\multicolumn{3}{|c|}{$\begin{array}{r}\text { ANCOVA } \\
\text { Survival }\end{array}$}} & \multicolumn{7}{|c|}{ ANOVA } \\
\hline & & & & \multicolumn{3}{|c|}{ Egg masses } & \multicolumn{2}{|c|}{ Embryos } & \multicolumn{2}{|c|}{ Young } \\
\hline & d.f. & $F$ & $P$ & d.f. & $F$ & $P$ & $F$ & $P$ & $F$ & $P$ \\
\hline Groups & 1 & 9.211 & 0.004 & 1 & 2.196 & 0.144 & 2.624 & 0.111 & 1.453 & 0.233 \\
\hline Replicates (nested) & 4 & 1.130 & 0.351 & 4 & 0.075 & 0.990 & 0.257 & 0.904 & 0.044 & 0.996 \\
\hline Time or period & 1 & 330.5 & $<0.001$ & 1 & 14.021 & $<0.001$ & 3.641 & 0.061 & 0.609 & 0.438 \\
\hline Interaction groups $\mathrm{x}$ period & & & & 1 & 0.230 & 0.634 & 0.036 & 0.849 & 0.024 & 0.878 \\
\hline
\end{tabular}

Replicates were nested within groups. Time (days) was a covariate for survival, but was treated as a factor with two levels for the other variables (before and after the 4th fortnight). Variables were measured every fortnight. Survival was arcsin-transformed for ANCOVA and variables for ANOVA were log-transformed. Bold type indicates significant values; d.f.: degree of freedom; $F$ : F-test; $P$ : probability

differences between group $\mathrm{M}$ and groups BM and $\mathrm{MM}$ (Table III).

For B. glabrata, mortality was low in all groups, usually varying between zero and two individuals replaced during the 11 fortnights of the experiment. Nevertheless, there were significant differences between replicates, period (before and after the 4th fortnight), and between groups in the second period (significant period $x$ groups interaction) (Tables IV, V). One of the replicates of group B - where B. glabrata was raised alone on one side of the container was the main cause of this significant difference. This replicate differed significantly from the other replicates and groups in Tukey a posteriori tests (B1 in Table V).

The production of egg masses and embryos per individual of $B$. glabrata differed significantly between groups, period, and in the interaction groups $\mathrm{x}$ period (Table IV). Group BMU (B. glabrata raised with $M$. tuberculata in an undivided container) and group BM (container divided by the wire mesh) were significantly more productive than the control groups B and BB. Group BMU produced significantly more egg masses and embryos per individual of B. glabrata, whereas group BM produced significantly more embryos per individual (Figs 2a, b, Table VI). The production of B. glabrata in group BMU was more pronounced between the 2nd and 4th fortnight of the experiment, whereas in group BM the production was higher than groups B and BB during the whole experiment (Figs 2a, b). Groups BMU and BM differed between each other only in the production of egg masses.

Most groups produced few young $B$. glabrata, yet they differed significantly in the production of young 

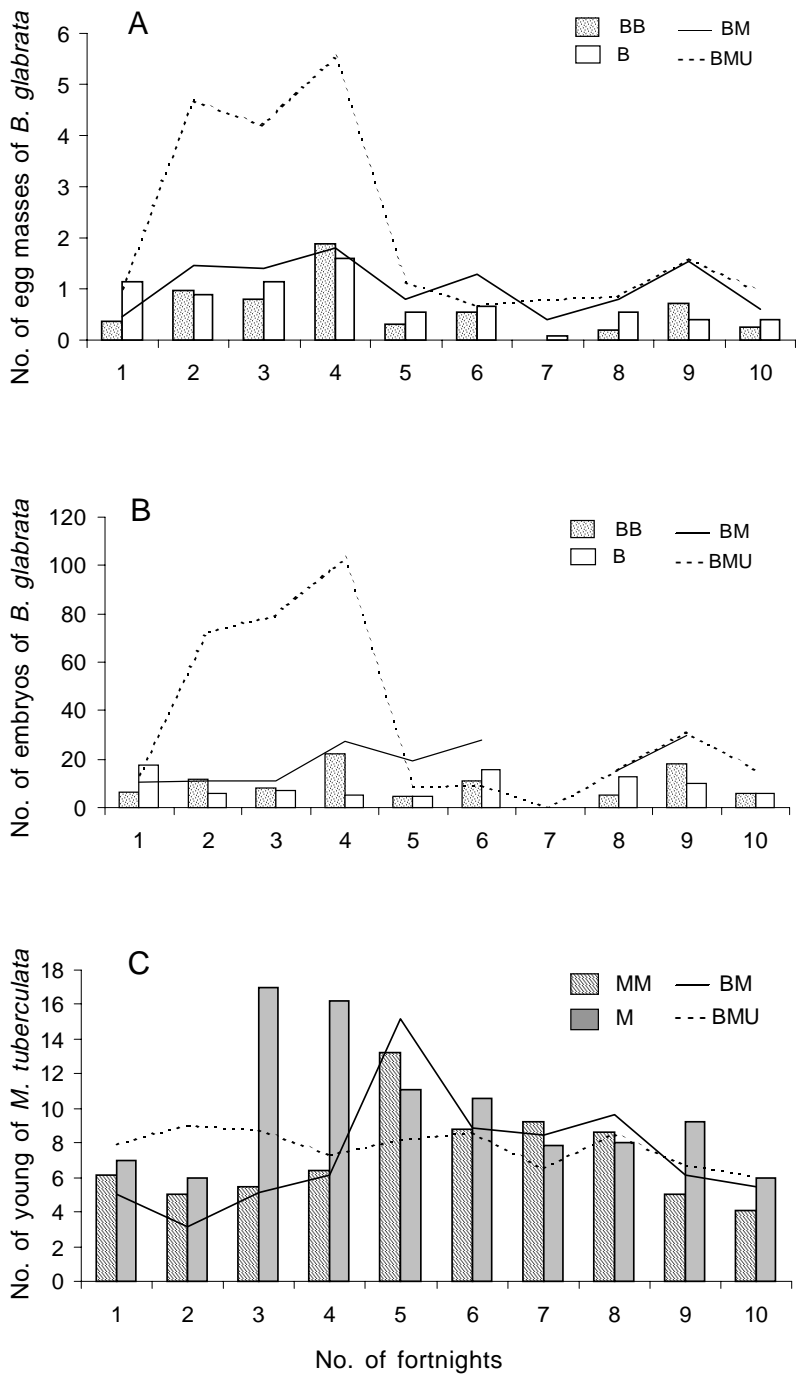

Fig. 2: fecundity of Biomphalaria glabrata and Melanoides tuberculata in the six treatments of Experiment 2. Two measures of fecundity were used for B. glabrata: the number of egg masses (A) and embryos (B). One measure of fecundity was used for $M$. tuberculata: the number of young $(C)$. Containers divided in two sides: B: B. glabrata/empty; BB: B. glabrata/B. glabrata; BM: B. glabrata/M. tuberculata; M: M. tuberculata/empty; MM: $M$. tuberculata/M. tuberculata. Containers undivided: BMU: B. glabratal M. tuberculata
(Table IV). Similarly to mortality in B. glabrata, the same replicate of group B (B1) was the main cause of this significance. It produced significantly more young compared to other replicates of the same group, and compared to other groups as well (Table V).

\section{DISCUSSION}

The hypothesis that $M$. tuberculata has a negative effect on B. glabrata (H1) was not supported in the conditions of Experiments 1 and 2. In Experiment 1, there was competition for food, but, contrary to expectation, $M$. tuberculata was eliminated by B. glabrata. Only the re-

\section{TABLE II}

Effect of the direct contact with Biomphalaria glabrata on the fecundity of Melanoides tuberculata (groups)

\begin{tabular}{lccr} 
& & \multicolumn{2}{c}{$\begin{array}{c}\text { Young (number } \\
\text { pNoduced per individual) }\end{array}$} \\
\cline { 3 - 4 } Groups & d.f. & $F$ & $P$ \\
Replicates (nested) & 3 & 5.245 & $\mathbf{0 . 0 0 3}$ \\
Period & 4 & 2.591 & $\mathbf{0 . 0 4 4}$ \\
Interaction groups x Period & 3 & 4.049 & $\mathbf{0 . 0 4 8}$ \\
\hline
\end{tabular}

Replicates were nested within groups. Variables were measured every fortnight. Period had two levels, before and after the 4th fortnight. Young was measured every fortnight and was logtransformed. Bold type indicates significant values; d.f.: degree of freedom; $F$ : F-test; $P$ : probability

\section{TABLE III}

Probabilities (Tukey test) for the null hypothesis of no differences between groups in the number of young produced per individual Melanoides tuberculata (log-transformed) in Experiment 2

\begin{tabular}{lcccc}
\hline Groups & $\mathrm{M}$ & $\mathrm{M} \mathrm{M}$ & $\mathrm{BM}$ & $\mathrm{BMU}$ \\
\hline M & 1.000 & - & - & - \\
M M & $\mathbf{0 . 0 1 2}$ & 1.000 & - & - \\
B M & $\mathbf{0 . 0 0 4}$ & 0.983 & 1.000 & - \\
BMU & 0.385 & 0.404 & 0.222 & 1.000
\end{tabular}

Bold type indicates significant values; containers divided in two sides: BM: B. glabrata/M. tuberculata; M: M. tuberculata/empty; MM: M. tuberculata/M. tuberculata. Containers undivided: BMU: B. glabrata/M. tuberculata

TABLE IV

Effect of the direct contact with Melanoides tuberculata on mortality and fecundity of Biomphalaria glabrata (groups)

\begin{tabular}{|c|c|c|c|c|c|c|c|c|c|}
\hline \multirow[t]{2}{*}{ ANOVA } & \multirow[t]{2}{*}{ d.f. } & \multicolumn{2}{|c|}{ Mortality } & \multicolumn{2}{|c|}{ Number of egg masses } & \multicolumn{2}{|c|}{ Embryos } & \multicolumn{2}{|c|}{ Young } \\
\hline & & $F$ & $P$ & $F$ & $P$ & $F$ & $P$ & $F$ & $P$ \\
\hline Groups & 3 & 2.272 & 0.088 & 14.306 & $<0.001$ & 9.104 & $<0.001$ & 6.567 & 0.001 \\
\hline Replicates (nested) & 4 & 6.138 & $<0.001$ & 0.120 & 0.975 & 0.319 & 0.864 & 4.868 & 0.002 \\
\hline Period & 1 & 9.869 & 0.002 & 38.967 & $<0.001$ & 5.489 & 0.022 & 5.381 & 0.023 \\
\hline Interaction Groups x Period & 3 & 3.420 & 0.022 & 3.909 & 0.012 & 4.719 & 0.005 & 1.155 & 0.333 \\
\hline
\end{tabular}

Replicates were nested within groups. Variables were measured every fortnight. Period had two levels, before and after the 4th fortnight. Mortality was the number of individuals replaced every fortnight, fecundity measures were calculated per individual, and all variables were log-transformed. Bold type indicates significant values; d.f.: degree of freedom; $F$ : F-test; $P$ : probability 
TABLE V

Probabilities (Tukey test) for the null hypothesis of no differences between groups in mortality and in the number of young produced per individual Biomphalaria glabrata in Experiment 2

\begin{tabular}{|c|c|c|c|c|c|c|c|c|c|}
\hline & $\begin{array}{l}\text { Groups and } \\
\text { replicates }\end{array}$ & B1 & BB1 & BM1 & BMU1 & B2 & BB2 & BM2 & BMU2 \\
\hline \multirow[t]{8}{*}{ Mortality (number of individuals replaced) } & B1 & 1.000 & - & - & - & - & - & - & - \\
\hline & BB1 & 0.015 & 1.000 & - & - & - & - & - & - \\
\hline & BM1 & 0.068 & 0.999 & 1.000 & - & - & - & - & - \\
\hline & BMU1 & 0.018 & 1.000 & 1.000 & 1.000 & - & - & - & - \\
\hline & B2 & 0.004 & 1.000 & 0.983 & 1.000 & 1.000 & - & - & - \\
\hline & BB2 & 0.048 & 1.000 & 1.000 & 1.000 & 0.993 & 1.000 & - & - \\
\hline & $\mathrm{BM} 2$ & 0.011 & 1.000 & 0.998 & 1.000 & 1.000 & 1.000 & 1.000 & - \\
\hline & BMU2 & 0.998 & 0.092 & 0.287 & 0.097 & 0.035 & 0.223 & 0.071 & 1.000 \\
\hline \multirow[t]{8}{*}{ Young (number produced per individual) } & B1 & 1.000 & - & - & - & - & - & - & - \\
\hline & BB1 & $<0.001$ & 1.000 & - & - & - & - & - & - \\
\hline & BM1 & $<0.001$ & 1.000 & 1.000 & - & - & - & - & - \\
\hline & BMU1 & 0.001 & 0.997 & 0.999 & 1.000 & - & - & - & - \\
\hline & $\mathrm{B} 2$ & 0.001 & 0.996 & 0.998 & 1.000 & 1.000 & - & - & - \\
\hline & BB2 & $<0.001$ & 1.000 & 1.000 & 0.998 & 0.997 & 1.000 & - & - \\
\hline & BM2 & $<0.001$ & 1.000 & 1.000 & 1.000 & 1.000 & 1.000 & 1.000 & - \\
\hline & BMU2 & 0.015 & 0.824 & 0.865 & 0.994 & 0.996 & 0.849 & 0.963 & 1.000 \\
\hline
\end{tabular}

Capital letters code for the treatments of Experiment 2, and numbers code for the replicates. Variables were measured every fortnight and were log-transformed. Bold type indicates significant differences. Containers divided in two sides: B: B. glabrata/empty; BB: B. glabrata/B. glabrata; BM: B. glabrata/M. tuberculata; M: M. tuberculata/empty; MM: M. tuberculata/M. tuberculata. Containers undivided: BMU: B. glabrata/M. tuberculata

sults of Experiment 1 would not be enough to reject $\mathrm{H} 1$, because it could be explained by stronger intraspecific competition in group B $(10$ B. glabrata $)$ than in group BM (5 B. glabrata +5 M. tuberculata) during the first 4 th fortnights. However, in Experiment 2, fecundity and mortality rates of $B$. glabrata were expected to be lower in the groups BM and BMU because of the negative effect of $M$. tuberculata. Instead, the highest fecundity of $B$. glabrata was in the group BMU.

The hypothesis that $M$. tuberculata liberates a substance that affects negatively individuals of $B$. glabrata (H2) was not supported either. According to H2, fecundity should be lower and mortality higher in the groups $\mathrm{BM}$ and BMU because of the presence of M. tuberculata. The result was in the opposite direction.

The higher production of egg masses and embryos by B. glabrata when raised with $M$. tuberculata in Experiment 2 (groups BMU and BM) could be explained by reduced crowding of $B$. glabrata per unit of volume in group BMU. However, crowding per unit of volume in groups B and $\mathrm{BM}$ is the same as in group BMU, but the production of egg masses and embryos was significantly higher in group BMU (Table VI). A second hypothesis is that crowding per unit of area, not volume, is reduced in group BMU, which indeed is true. Although the total density of individuals of the two species is the same in both groups, in the group BM, individuals of each species were restricted to one half of the container. Hence, each species was more crowded than in BMU, where individuals were allowed to use the whole container. Crowding in $B$. glabrata usually is related to volume of available water (Wright 1960), but it also may be related to available surface area (Sturrock \& Sturrock 1970). Surface area is not
TABLE VI

Probabilities (Tukey test) for the null hypothesis of no differences between groups in the number of egg masses and embryos produced per individual Biomphalaria glabrata in Experiment 2

\begin{tabular}{llcccc}
\hline & Groups & B & BB & BM & BMU \\
\hline Egg masses & B & 1.000 & - & - & - \\
& BB & 0.830 & 1.000 & - & - \\
& B M & 0.434 & 0.094 & 1.000 & - \\
& BMU & $<\mathbf{0 . 0 0 1}$ & $<\mathbf{0 . 0 0 1}$ & $\mathbf{0 . 0 0 3}$ & 1.000 \\
Embryos & B & 1.000 & - & - & - \\
& BB & 0.997 & 1.000 & - & - \\
& B M & $\mathbf{0 . 0 2 3}$ & $\mathbf{0 . 0 3 7}$ & 1.000 & - \\
& BMU & $<\mathbf{0 . 0 0 1}$ & $\mathbf{0 . 0 0 1}$ & 0.524 & 1.000 \\
\hline
\end{tabular}

Capital letters code for the treatments of Experiment 2. Variables were measured every fortnight and were log-transformed. Bold type indicates significant differences. Containers divided in two sides: B: B. glabrata/empty; BB: B. glabrata/B. glabrata; BM: B. glabrata/M. tuberculata. Containers undivided: BMU: $B$. glabrata/M. tuberculata.

usually considered in the design of experiments with snails. Reduced area could increase chances of hitting other individuals, increasing stress and reducing fecundity and growth (Chernin \& Michelson 1959). In this study, crowding in B. glabrata probably occurred as an area effect.

Crowding of $B$. glabrata per unit of area does not explain the significantly higher production of embryos in group BM compared to groups BB and B. Crowding per 
unit of area was the same in these three groups, and a logical hypothesis is that $M$. tuberculata is facilitating the production of embryos by $B$. glabrata. M. tuberculata could be releasing a nutrient for $B$. glabrata, or could be producing a substance that would stimulate growth of $B$. glabrata directly. Gomez et al. (1990) observed a decline in numbers of $B$. glabrata raised with $T$. granifera in the laboratory, the opposite result of this study. Conversely, Moné (1991) observed higher growth rates of B. glabrata raised with $M$. tuberculata, in agreement with this study. Moné (1991) also discussed the possible causes and suggested that M. tuberculata could liberate a nutritive substance that would stimulate growth of $B$. glabrata directly. Such substance may also stimulate the fecundity of $B$. glabrata as observed in this study. The same phenomena have been reported in other studies of competition between freshwater snails, but these observations have not received adequate attention (Santos et al. 1989, Stryker et al. 1991). It is possible that $M$. tuberculata indeed liberates a substance that affects $B$. glabrata. This substance might have a negative effect on B. glabrata in some conditions (e.g. Gómez et al. 1990) or positive in others (this study and Moné 1991). Therefore, the result of this interaction might be affected by environmental conditions. For example, Pointier et al. (1991b, 1992) observed that the efficiency of $M$. tuberculata in the elimination of $B$. glabrata depended on the type of habitat where the two occurred.

The advantage of $B$. glabrata over $M$. tuberculata in Experiment 1 was a result of the early reproduction, high reproductive rate and the high number of young $B$. glabrata produced at the 4 th fortnight of the experiment. As soon as rodent food pellets were provided, individuals of $B$. glabrata would aggregate over the food, covering it completely and making it unavailable for $M$. tuberculata. Conversely, in Experiment 2 B. glabrata was prevented from monopolizing food in the same manner by a low number of adults and a wire mesh dividing the container.

M. tuberculata did not reproduce in Experiment 1, and reproduced only intermittently in Experiment 2 . Mortality of M. tuberculata is usually low (Dudgeon 1986, Freitas et al. 1987), but it reproduces continuously (Bedê 1992, Pointier et al. 1992). It is possible that the source population of $M$. tuberculata reproduces late in the development. Indeed, age of first reproduction of M. tuberculata in Brazil was 710 days (Bedê 1992), whereas in Hong Kong it varied between 90 and 120 days (Dudgeon 1986), and in Malaysia between 100 and 200 days (Berry \& Kadri 1974). Fecundity of $M$. tuberculata did not differ between groups, hence, the presence of $B$. glabrata did not affect $M$. tuberculata in the conditions of the experiment.

In conclusion, our results confirm the differences in demographic strategies between B. glabrata and $M$. tuberculata reported in the literature. Individuals of $M$. tuberculata reproduce later and grow slower than $B$. glabrata, resulting in the elimination of M. tuberculata by $B$. glabrata in laboratory conditions. These results may not hold in the field because of the complexity of natural conditions.
M. tuberculata does not seem to inhibit B. glabrata producing chemical substances. Actually, in the conditions of the experiment of this study $M$. tuberculata might even facilitate the reproduction of $B$. glabrata. The conditions leading to this result need further clarification and field evidence. Nevertheless, detailed studies of the interaction between these species in the conditions of the local environment are necessary prior to introductions. Such introductions could lead to a result opposite to that expected, i.e., the increase in the size of populations of $B$. glabrata. Additional complications are the fact that $M$. tuberculata transmits other parasites that cause diseases in humans (Pointier 1999), and that it may have unpredicted effects on the endemic fauna.

\section{REFERENCES}

Bedê LC 1992. Dinâmica Populacional de Melanoides tuberculata (Prosobranchia: Thiaridae) no Reservatório da Pampulha, MSc Thesis, UFMG, Belo Horizonte, 112 pp.

Berry AJ, Kadri AH 1974. Reproduction in the Malayan freshwater cerithicean gastropod Melanoides tuberculata.J Zool 172: 369-381.

Chernin E, Michelson EH 1957. Studies on the biological control of schistosome-bearing snails. III. The effects of population density on growth and fecundity in Australorbis glabratus. Am J Hyg 65: 57-70.

Dudgeon D 1986. The life cycle, population dynamics and productivity of Melanoides tuberculata (Müller,1774) (Gastropoda: Prosobranchia: Thiaridae) in Hong Kong. J Zool Lond (A) 208: 37-53.

Freitas JR, Bedê LC, Marco JR, Rocha LA, Santos MBL 1987. Population dynamics of aquatic snails in Pampulha reservoir. Mem Inst Oswaldo Cruz 82: 299-305.

Gomez JD, Vargas M, Malek EA 1990. Biological control of Biomphalaria glabrata by Thiara granifera under laboratory conditions. Trop Med Parasitol 41: 43-45.

Madsen H 1990. Biological methods for the control of freshwater snails. Parasitol Today 6: 237-241.

Moné H 1991. Influence of non-target molluscs on the growth of Biomphalaria glabrata infected with Schistosoma mansoni: correlation between growth and cercarial production. J Moll Stud 57: 1-10.

Moné H, Théron A, Combes C 1986. Interaction between the Biomphalaria glabrata-Schistosoma mansoni host-parasite system and the non-target molluscs: influence on cercarial production. J Parasitol 72: 410-416.

Perez JG, Vargas M, Malek EA 1991. Displacement of Biomphalaria glabrata by Thiara granifera under natural conditions in the Dominican Republic. Mem Inst Oswaldo Cruz 86: 341-347.

Pointier JP 1993. The introduction of Melanoides tuberculata (Mollusca:Thiaridae) to the island of Saint Lucia (West Indies) and its role in the decline of Biomphalaria glabrata, the snail intermediate hosts of Schistosoma mansoni. Acta Trop 54: 13-18.

Pointier JP 1999. Invading freshwater gastropods: some conflicting aspects for public health. Malacologia 41: 403-411.

Pointier JP, Giboda M 1999. The case for biological control of snail intermediate hosts of Schistosoma mansoni. Parasitol Today 15: 395-397.

Pointier JP, Guyard A 1992. Biological control of the snail intermediate hosts of Schistosoma mansoni in Martinique, French West Indies. Trop Med Parasitol 43: 98-101. 
Pointier JP, Mc Cullough F 1989. Biological control of the snail hosts of Schistosoma mansoni in the Caribbean area using Thiara spp. Acta Trop 46: 147-155.

Pointier JP, Balzan C, Chrosciechowski P, Incani RN 1991c. Limiting factors in biological control of the snail intermediate hosts of Schistosoma mansoni in Venezuela. J Med Appl Malacol 3: 53-67.

Pointier JP, Delay B, Toffart JL, Lefèvre M, Romero-Alvarez R 1992. Life history traits of three morphs of Melanoides tuberculata (Gastropoda: Thiaridae), an invading snail in the French West Indies. J Moll Stud 58: 415-423.

Pointier JP, Frederic M, Mazille V 1991a. Biological control of Biomphalaria glabrata by Melanoides tuberculata on Désirade Island, French West Indies. J Med Appl Malacol 3: 49-52.

Pointier JP, Guyard A, Mosser A 1989. Biological control of Biomphalaria glabrata and B. straminea by the competitor snail Thiara tuberculata in a transmission site of schistosomiasis in Martinique, French West Indies. Ann Trop Med Parasitol 83: 263-269.

Pointier JP, Toffart, JL, Lefèvre M 1991b. Life tables of freshwater snails of the genus Biomphalaria (B. glabrata, $B$. alexandrina, $B$. straminea) and of one of its competitors Melanoides tuberculata under laboratory conditions. Malacologia 33: 43-54.

Prentice MA 1983. Displacement of Biomphalaria glabrata by the snail Thiara granifera in field habitats in St. Lucia, West Indies. Ann Trop Med Parasitol 77: 51-59.

Santos MB, Freitas JR, Alves ES, Rocha LA 1989. Competi- tive behavior of Biomphalaria glabrata and Biomphalaria tenagophila - Laboratory studies. Mem Inst Oswaldo Cruz. 84: 156-178.

Schlegel L, Pointier JP, Petitjean-Roget V, Nadeau Y, Blateau A, Mansuy JM 1997. Le contrôle de la schistosomose intestinale de l'île de la Martinique. Parasite 4: 217-225.

Sokal RR, Rohlf FJ 1995. Biometry, 3rd ed., WH Freeman and Co., New York, 887 pp.

Stryker GA, Koech DK, Loker ES 1991. Growth of Biomphalaria glabrata populations in the presence of the ampullariid snails Pila ovata, Lanistes carinatus and Marisa cornuarietis. Acta Trop 49: 137-147.

Sturrock RF 1995. Current concepts of snail control. Mem Inst Oswaldo Cruz 90: 241-248.

Sturrock RF, Sturrock BM 1970. Observations on some factors affecting the growth rate and fecundity of Biomphalaria glabrata (Say). Ann Trop Med Parasitol 64: 349-355.

Vaz JF, Teles HMS, Correa MA, Silva Leite SP 1986. Ocorrência no Brasil de Thiara (Melanoides) tuberculata (Muller 1774) (Gastropoda, Prosobranchia), primeiro hospedeiro intermediário de Clonorchis sinensis (Cobbold,1875) (Trematoda, Plathyhelmintes). Rev Saúde Publ São Paulo 20:318-322.

WHO-World Health Organization 1984. Report of an informal consultation on research on the biological control of snail intermediate hosts. TDR/BCV-SCH/SIH/84: 13-16.

Wright CA 1960 . The crowding phenomenon in laboratory colonies of freshwater snails. Ann Trop Med Parasitol 54: 224232. 